\title{
AÇÃO E MOVIMENTO: POSSIBILIDADES PARA A CONSTRUÇÃO DE CONCEITOS MATEMÁTICOS ATRAVÉS DOS PROJETOS DE GEOMETRIA DINÂMICA PELOS DISCENTES NA LICENCIATURA
}

\author{
Rodrigo Sychocki da Silva ${ }^{1}$, EdUARdo MEliga PompermayeR $^{2}$ \\ Instituto Federal de Educação, Ciência e Tecnologia do Rio Grande do Sul \\ ${ }^{1}$ Campus de Caxias do Sul \\ ${ }^{2}$ Campus de Canoas \\ <rodrigo.silva@caxias.ifrs.edu.br>, <eduardo.pompermayerr@canoas.ifrs.edu.br>
}

DOI: $10.21439 /$ conexoes.v9i4.1010

\begin{abstract}
Resumo. A proposta do artigo é apresentar e discutir os resultados de uma pesquisa com duração de dois semestres envolvendo duas turmas de estudantes da graduação em Licenciatura em Matemática do Instituto Federal de Educação, Ciência e Tecnologia do Rio Grande do Sul, Campus Caxias do Sul. Mostra-se com a pesquisa que a construção de um projeto envolvendo geometria dinâmica aliado ao uso da tecnologia informática possibilitou a apropriação de diversos conceitos matemáticos abordados na disciplina de Geometria Plana. Através dos conceitos da epistemologia genética de Jean Piaget, em especial a teoria da tomada de consciência foi possível analisar a evolução dos estudantes ao longo do processo e verificar que o uso da tecnologia potencializa a construção dos conceitos matemáticos. Ao final verificou-se que proposta de trabalho ocorrida ao longo do semestre tornou possível desenvolver nos sujeitos envolvidos novas competências e habilidades, dentre elas, a habilidade de possivelmente utilizar a tecnologia em sala de aula.
\end{abstract}

Palavras-chaves: Formação de professores de Matemática. Geometria Dinâmica. Tomada de Consciência. Tecnologia no Ensino da Matemática.

\begin{abstract}
The purpose of the paper is to present and discuss the results of a search lasting two semesters involving two groups of students Graduation Degree in Mathematics from the Federal Institute of Education, Science and Technology of Rio Grande do Sul, Caxias do Sul Campus. It is shown through research that the construction of a project involving dynamic geometry coupled with the use of computer technology enabled the appropriation of various mathematical concepts covered in plane geometry discipline. Through the concepts of genetic epistemology of Jean Piaget, especially the theory of awareness was possible to analyze the evolution of students throughout the process and check that the use of technology enhances the construction of mathematical concepts. At the end it was found that proposed work occurred during the half made it possible to develop the subjects involved new skills and abilities, among them the ability to possibly use technology in the classroom.
\end{abstract}

Keywords: Mathematics teacher training. Dynamic Geometry. Consciousness. Technology in Mathematics Teaching.

\section{INTRODUÇÃO}

O uso da tecnologia informática em sala de aula, em especial nas aulas de matemática potencializa a construção do conhecimento e possibilita a criação de novas dimensões no ambiente educacional escolar. Ao oportunizar aos estudantes momentos de elaboração e cri- ação matemática possibilita-se que o educando desempenhe um papel importante no decorrer do seu processo de aprendizagem. Nesse sentido, Barbosa (2005) colabora:

Caberia, então, aos professores-educadores da área de educação matemática proporcionar contextos favoráveis para que o processo educativo tomasse outra dimensão, 
AÇÃO E MOVIMENTO: POSSIBILIDADES PARA A CONSTRUÇÃO DE CONCEITOS MATEMÁTICOS ATRAVÉS DOS PROJETOS DE GEOMETRIA DINÂMICA PELOS DISCENTES NA LICENCIATURA

uma dimensão atual, mais inovadora, compatível com os avanços da ciência e da tecnologia. (BARBOSA 2005 p. 75)

Com base na citação anterior entende-se que a proposta apresentada neste trabalho propõe uma possibilidade para que as aulas de geometria plana sejam aperfeiçoadas e atendam cada vez mais com as necessidades contemporâneas no ensino da matemática. A inserção da proposta de construção de um projeto com o auxílio de um software de geometria dinâmica possibilitou que os alunos do curso superior em Licenciatura em Matemática do Instituto Federal de Educação, Ciência e Tecnologia do Campus Caxias do Sul desenvolvessem novas competências e habilidades matemáticas durante a elaboração e construção dos mecanismos.

A disciplina de Geometria Plana é ofertada na atual matriz curricular ${ }^{1}$ no primeiro semestre do curso de graduação. A realidade observada nas turmas que cursam a disciplina é que os assuntos de geometria plana desenvolvidos anteriormente no ensino básico foram apresentados de maneira que não se estimulasse as formas de construção e elaboração de conceitos por parte dos estudantes. Nesse sentido, a proposta de integrar à disciplina de Geometria Plana a construção de um projeto de geometria dinâmica, onde os estudantes pudessem relacionar e criar construções dinâmicas através da matemática desenvolvida durante o semestre demonstra ser profícuo o uso da tecnologia nas aulas de geometria, em especial pode influenciar a futura prática docente, envolvendo os estudantes desde o início da graduação em atividades que promovam a construção do conhecimento. Sobre o uso de ambientes de geometria dinâmica, Giraldo (2012) argumenta:

\footnotetext{
A grande vantagem apontada em relação às construções geométricas com papel e lápis está justamente no aspecto dinâmico do ambiente: uma vez concluída uma construção no computador, é possível alterar um de seus elementos (em geral, por meio do arrastar do mouse) e observar as alterações consequentes nos demais elementos. Assim, uma figura construída em geometria dinâmica representa, de forma mais efetiva, uma classe de objetos geométricos definida por propriedades e relações comuns - que se preservam quando esses objetos são arrastados na tela. Como muitos autores têm apontado, esse aspecto permite ao aluno investigar um grande número de exemplos e explorar conjecturas, construindo uma preparação para o exercício de argumentação matemática. (GIRALDO, 2012 p. 39)
}

Com isso, inspirado nas ideias de autores sobre o uso da tecnologia a favor do ensino, em especial o ensino de conteúdos matemáticos, apresenta-se neste

\footnotetext{
${ }^{1}$ Aqui se fala da matriz curricular vigente no período de 2010 a 2015 na instituição. Disponível em: <http://www.caxias.ifrs.edu.br/ site/midias/arquivos/2015739321376ppc_matematica_2014.pdf>
}

texto os resultados de uma pesquisa envolvendo os alunos da graduação em Licenciatura em Matemática. A teoria de Jean Piaget sobre a tomada de consciência é utilizada para verificar o processo de evolução e aprendizagem durante a proposta. Destaca-se ao longo do texto que ao elaborar e desenvolver a criação de um projeto envolvendo conteúdos de Geometria Plana em um ambiente de geometria dinâmica os estudantes atravessam diversos e sucessivos níveis de tomada de consciência, onde a reestruturação e organização do conhecimento é condição essencial para o desenvolvimento de novos conceitos matemáticos.

O presente trabalho está organizado em quatro seções: os fundamentos teóricos do artigo estão apresentados em duas partes; a primeira apresenta ideias de autores e suas contribuições para o uso do computador no ensino de conteúdos matemáticos. Na segunda parte apresenta-se e discutem-se as características da tomada de consciência proposta por Piaget. A segunda seção apresenta os materiais e métodos utilizados na pesquisa. A terceira seção apresenta uma análise sobre as produções dos estudantes à luz da teoria da tomada de consciência, evidenciando a influência do ambiente informatizado para a construção dos conceitos matemáticos. Na quarta seção apresentam-se reflexões e lições aprendidas sobre o trabalho produzido através de conclusões parciais.

\section{Fundamentos teóricos}

\subsection{Sobre a tecnologia informática na sala de aula}

Seymour Papert foi um dos pioneiros em defesa do uso do computador no ensino, tanto de matemática como de outras áreas do conhecimento. O autor propõe ideias inovadoras sobre o uso desse tipo de tecnologia pode oferecer para os sistemas de ensino. De acordo com Papert (2008) há os Schoolers? que apesar de reconhecerem que a escola atual tem problemas e se mostrarem dispostos a resolvê-los, são resistentes a grandes mudanças. A concepção desse grupo é que a escola necessita de mudanças imediatas e urgentes. Neste caso, preferem saber como o uso de computadores, por exemplo, poderia resolver de imediato alguns desses problemas.

Em oposição aos Schoolers existem os Yearners ${ }^{3}$ que desejam algo diferente no ensino. Porém, são

\footnotetext{
${ }^{2} \mathrm{O}$ neologismo Schooler é uma forma verbal infinitiva do substantivo School (Escola), que neste texto tem o significado aproximadamente de "defensores da instituição escolar na sua estrutura atual". (PAPERT 2008 p. 17)

"O neologismo Yearner origina-se do verbo em inglês yearn desejar fortemente algo difícil de torna-se realidade, como ânsia de liberdade por pessoas que vivem em um regime autoritário." (PAPERT. 2008 p. 17)
} 
AÇÃO E MOVIMENTO: POSSIBILIDADES PARA A CONSTRUÇÃO DE CONCEITOS MATEMÁTICOS ATRAVÉS DOS PROJETOS DE GEOMETRIA DINÂMICA PELOS DISCENTES NA LICENCIATURA

muitas vezes impedidos pelos "obstáculos às mudanças na educação, como recursos financeiros, políticas, o imenso poder dos interesses implícitos de burocratas da escola ou a falta de pesquisas científicas sobre novas formas de aprender" (PAPERT, 2008, p. 18 - 19). Papert destaca que Yearners conseguem contornar as dificuldades apresentadas na escola, desenvolvendo pequenos oásis propícios à aprendizagem em suas salas de aula.

Apesar de Papert ter escrito suas ideias há 20 anos e se referir à realidade da educação americana, notase problemas muito semelhantes no atual ensino brasileiro, onde o currículo com uma grande quantidade de conteúdos faz com que o professor fique preso, não tendo o tempo necessário para realizar uma abordagem satisfatória dos assuntos. De acordo com o autor, dar-se o tempo necessário a si mesmo é um princípio muito importante para o aprendizado de matemática.

\section{Entretanto, a escola flagrantemente o transgride por suas maneiras de retalhar o tempo: "Peguem seus livros... re- solva 10 exercícios no final do Capítulo 18 ... triiim... o sinal tocou, fechem seus livros". Imagine um executivo, um neurocirurgião ou um cientista que tivesse que traba- lhar com uma agenda tão fragmentada. (PAPERT 2008. p. 92)}

Papert defendeu o uso de computador não apenas como uma ferramenta usada como calculadora ou editor de texto, e sim como fonte inspiradora e que a partir de uma situação inicial, o uso dos computadores pudessem colaborar na produção de novos conhecimentos. Nesse sentido, as mudanças propostas são grandes e necessitariam de novas concepções quanto à aprendizagem, ensino e a organização da escola. Exigiriam mudanças nas relações entre professores, alunos e toda comunidade escolar, ou seja, vão além das mudanças de materiais e metodologias. Em contraponto a isso o autor destaca que "A sociedade tem muitos meios de resistir a mudanças fundamentais e ameaçadoras." (PAPERT, 1988, p. 17).

Se a tecnologia permitiu que gradualmente as mudanças ocorressem no ambiente escolar, a presença somente da tecnologia não torna a aprendizagem efetiva, é necessário alguma ação por parte do professor, na qual ele seja capaz de integrar à sua metodologia de trabalho o uso das tecnologias como ferramentas que possam colaborar na construção e aprendizagem dos conceitos envolvidos. Sobre isso, Bona (2012) disserta:

As tecnologias digitais condicionam o modo de fazer atual, mas as mudanças não ocorrem simplesmente pela sua presença na escola, e criam condições para que a produção intelectual se dê por caminhos e formas que não eram possíveis sem ela. (BONA 2012 p. 89)
Ou seja, as tecnologias digitais têm potencial para modificar o modo como as instituições de ensino são organizadas atualmente; porém, nem sempre isso é fácil de alcançar.

Os sistemas educacionais são difíceis de serem transformados; podemos dizer o mesmo da prática de seus atores. A forma de 'fazer escola' e formar professores, há muitas gerações, imprimem às instituições uma inércia enorme e mesmo aversão a mudanças em sua estrutura. (GOMES; SOUZA; SIQUEIRA 2012 p. 101)

A inércia e aversão a mudanças por parte dos sistemas educacionais foram percebidas na prática pelos autores do trabalho. Isso vai ao encontro do que Veen e Vrakking (2009) destacam:

O que pode hoje ser visto na educação é uma luta; uma luta para encaixar a nova tecnologia em um velho modelo; uma luta até mesmo para servir às demandas de mudanças da sociedade no modelo existente. E essa luta não está obtendo resultado. (VEEN; VRAKKING. 2009. p. 90)

Os autores dissertam que isso não significa que não existam exemplos que apresentam êxito na utilização de ambientes informatizados. Saber utilizar novas tecnologias de uma forma similar às propostas por Papert pode ser um caminho para a melhora do ensino de um modo geral, a fim de modificar, ao menos em parte, o sistema educacional. Milani (2001) reafirma a ideia que se bem empregada, a tecnologia informática pode trazer grandes contribuições para o ensino. Segundo a autora, para isso ocorrer são necessárias mudanças na estrutura do ambiente escolar, dentre elas a concepção de que "O computador exige que o aluno tenha participação ativa. A utilização da informática favorece, ao mudar o "estilo" das aulas, a mudança de papéis do aluno e do professor." (MILANI, 2001, p. 176)

Nesse cenário destaca-se que há uma diferença no que as novas gerações aprendem, "visto que passamos a mudar nossas demandas como sociedade e também por causa do uso cada vez maior de tecnologia." (VEEN; VRAKKING, 2009, p. 90). E, nesta nova demanda de aprendizagem, o computador exerce um papel fundamental.

Quando o computador é usado como ferramenta, a aula não é igual para todos. Cada aluno pode construir seus conhecimentos segundo seu próprio estilo de aprendizagem, expressar suas ideias ou resolver um problema de acordo com seu grau de conhecimento e interesse, no seu ritmo. (MILANI 2001 p. 176)

Ou seja, infere-se através das ideias dos autores apresentados anteriormente, ao saber usar o computador e suas ferramentas disponíveis, de forma que o estudante tenha um papel mais ativo na construção de seu conhecimento, possa ser uma forma de aperfeiçoar o ensino de Matemática. 
AÇÃO E MOVIMENTO: POSSIBILIDADES PARA A CONSTRUÇÃO DE CONCEITOS MATEMÁTICOS ATRAVÉS DOS PROJETOS DE GEOMETRIA DINÂMICA PELOS DISCENTES NA LICENCIATURA

\subsection{Jean Piaget e a tomada de consciência}

Esta seção foi inspirada em Piaget (1977) e Piaget (1978), onde o autor apresenta nos livros A Tomada de Consciência (1977) e Fazer e Compreender (1978) os conceitos e a teoria envolvendo o assunto desta seção.

Inicialmente é importante considerar que para Piaget, a evolução cognitiva do sujeito depende da ação. A ação por sua vez ocorre entre o sujeito, concebido como epistemológico, e os objetos, que estão fora do sujeito e que contribuem para o processo de constituição do indivíduo. Concebendo a ação como elemento central no processo de evolução das tomadas de consciência pelo sujeito, claramente o autor difere "insight" de "tomada de consciência". Para Piaget, o primeiro trata-se de uma iluminação onde não se acrescenta nada ao sujeito, diferentemente do segundo processo, que trata da evolução do pensamento, fundamentado nas ações do sujeito sobre os objetos.

Como sujeito e objeto são disjuntos, Piaget considera que no processo de tomada de consciência existe uma região denominada periferia. É uma região limítrofe entre objeto e sujeito, onde o conjunto das ações do sujeito sobre o objeto se inicia já desde os primeiros estádios de desenvolvimento quando criança. Pelo fato de Piaget centralizar o processo na ação, essa por sua vez estabelece uma ponte entre o real e a construção. Trata-se de um processo onde através de ações assimiladoras e acomodadoras há a possibilidade de ocorrer a interiorização e exteriorização dos mecanismos referentes à ação do sujeito sobre os objetos. Antes da ocorrência de ação entre sujeito e objeto, Piaget define o centro do sujeito e o centro do objeto. O primeiro refere-se ao sujeito, que do ponto de vista epistemológico está almejando uma conquista. O segundo centro refere-se ao que está para ser conquistado. Piaget expõe que é possível avançar muito na busca por estes centros, embora nunca se consiga alcançá-los plenamente.

Em se tratando de ação, a primeira é considerada assimiladora e parte do sujeito em relação ao objeto. Essa ação é fundamental e pode ter perturbações, uma vez que o processo de exteriorização é onde o sujeito conhece e trata com o objeto. Na sequência, a ação acomodadora é a ação em que o objeto age sobre o sujeito, possivelmente modificando os seus esquemas assimiladores. Nesse processo, a acomodação possibilita ao sujeito modificar a sua ação perante os objetos, e isso ocorre uma vez que as ações sendo intercaladas e os esquemas sendo modificados possibilitam que a cada etapa entre assimilação e acomodação aconteça um micro avanço na direção dos centros do sujeito e do objeto. A Figura 1, inspirada em Piaget (1977, p. 199), apresenta-se um esquema organizando as ideias e con-

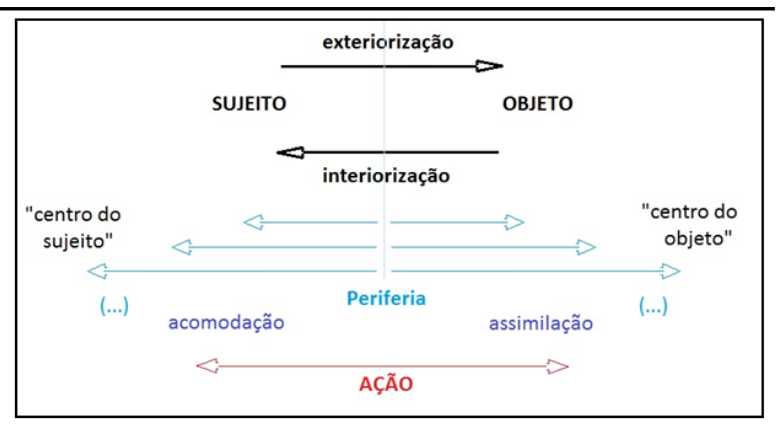

Figura 1: Esquema sobre a ação do sujeito com o objeto. Fonte: Piaget (1977. p. 199)

ceitos anteriormente discutidos.

Piaget considera que somente é possível coordenar as ações quando existe diferenciação. Com isso ele apresenta dois tipos de coordenações: as coordenações inferenciais e as coordenações causais. A primeira trata-se de um processo relativo ao sujeito e a sua subjetividade e a segunda trata-se de um processo relativo ao objeto e sua objetividade. Para que haja compreensão é necessário observar. Logo, através das coordenações inferenciais é que somos capazes de elaborar conceitos, que por sua vez permitem que ocorram nossos pensamentos. Piaget considera que o processo da tomada de consciência através das ações pode ser caracterizado por níveis correlativos e sequenciais, tratados por ele como nível I, nível II e nível III. Cada um desses níveis por sua vez pode ter diferentes subníveis, onde os sujeitos podem ser caracterizados de acordo com os seus êxitos e justificativas apresentadas em cada ação diante o objeto.

Com isso, o sujeito através de duas ações caracteriza-se por estar em determinado nível, no qual ele se aproxima mais do centro do objeto e a apropriação de suas ações torna o processo em busca do objetivo mais eficiente. Os sujeitos, segundo Piaget, ao enfrentar situações novas e conflitantes, podem através de suas ações desenvolver regulações ativas capazes de ultrapassar a barreira imposta pelo recalque cognitivo, tornando possível através de suas ações se apropriarem delas e com isso tomar consciência.

Para Piaget, a criação da novidade, ou regulação ativa, ocorre em decorrência da ação e está relacionada com a capacidade do sujeito em elaborar através de um processo cognitivo a superação da contradição ou tentativa de equilibrar-se parcialmente durante a ação. Através dos níveis anteriormente citados, as regulações ativas e as coordenações das ações tornam-se melhores e mais eficientes possibilitando ao sujeito internalizar melhor suas ações e com isso se aproximar mais do cen- 
AÇÃO E MOVIMENTO: POSSIBILIDADES PARA A CONSTRUÇÃO DE CONCEITOS MATEMÁTICOS ATRAVÉS DOS PROJETOS DE GEOMETRIA DINÂMICA PELOS DISCENTES NA LICENCIATURA

tro do objeto em estudo.

Portanto, a tomada de consciência é um processo que decorrente da ação do sujeito sobre o objeto, tratase de uma complexa reorganização de suas estruturas cognitivas, criação de novos esquemas assimiladores, estimulação da regulação ativa, retirada de informações sobre a ação, organização das informações obtidas na ação e de equilíbrios/desequilíbrios ao longo do processo.

\section{MATERIAIS E MÉTODOS UTILIZADOS}

Os projetos de geometria dinâmica construídos foram elaborados durante a disciplina de Geometria Plana do primeiro semestre do curso de Licenciatura em Matemática do Instituto Federal de Educação, Ciência e Tecnologia do Campus de Caxias do Sul. O projeto consistia em realizar uma construção utilizando o software livre de geometria dinâmica GeoGebre 4

Estabeleceu-se que a construção deveria conter os elementos da geometria estudados durante o semestre, com a possibilidade de que estudantes pudessem acrescentar qualquer outro elemento matemático ou de outras áreas do conhecimento. Solicitou-se que além do arquivo contendo a construção, cada grupo deveria entregar um relatório textual contendo a exploração de um roteiro de questionamentos propostos pelos professores da disciplina. Em linhas gerais, no relatório os estudantes deveriam explorar os seguintes questionamentos:

1 - Qual o objeto foi escolhido para a investigação? O que chamou a atenção de vocês quanto a esse objeto? Explique.

2 - Onde esse objeto é utilizado? Qual a sua finalidade/objetivo no cotidiano? Explique. (pode consultar outras fontes: livros, sites, etc.)

3 - Na construção do objeto virtual quais foram as maiores dificuldades do grupo diante da modelagem escolhida? Explique.

4 - Na construção do objeto virtual quais foram as maiores facilidades do grupo diante da modelagem escolhida? Explique.

5 - Quais os conceitos matemáticos que foram utilizados pelo grupo durante a construção do objeto? Explique destacando possíveis relações desses conceitos com o funcionamento do objeto.

6 - Durante a construção do objeto virtual foi necessário conhecer algum conceito que não tinha sido

${ }^{4}$ Software livre. Disponível em: <http://www.geogebra.org/cms/ pt_BR/download/> abordado nas aulas de geometria plana? Explique comentando quais seriam tais conceitos.

A produção textual tinha como objetivo estimular os estudantes na construção de justificativas e argumentações sobre as ideias desenvolvidas no projeto. A produção dos projetos ocorreu durante o primeiro semestre de 2014 ( $1^{\circ}$ turma observada) e o primeiro semestre de 2015 ( $2^{\circ}$ turma observada), onde o professor responsável pelas turmas realizou três aulas no laboratório de informática da instituição, com o objetivo de que os estudantes pudessem discutir e aperfeiçoar suas ideias em conjunto. Além disso, os estudantes poderiam complementar o seu trabalho em momentos extraclasse.

Ao final do semestre, pode-se verificar através da proposta de trabalho assumida durante a pesquisa que os estudantes desenvolveram os seus projetos utilizando não somente as ideias e conceitos abordados, mas também outros conceitos e ideias por eles pesquisados. Isso demonstra que o potencial desse tipo de atividade mobiliza o sujeito durante o processo da busca pelo conhecimento, evidenciando o papel do estudante como personagem central durante a sua própria aprendizagem.

\section{ANÁLISE DA PRODUÇÃO DOS ESTUDAN- TES}

O objetivo da presente seção é apresentar e discutir os resultados obtidos com a pesquisa, e também analisar a produção dos estudantes através do referencial teórico apresentado anteriormente, possibilitando que uma reflexão sobre a proposta aqui relatada possa ser feita por professores/pesquisadores interessados no assunto da presente pesquisa.

\subsection{A turma de discentes 2014/1}

Ao final do primeiro semestre letivo de 2014 os estudantes entregaram ao professor da disciplina uma produção textual na forma de relatório abordando aspectos teóricos sobre sua construção no projeto de geometria dinâmica juntamente com o arquivo da construção geométrica produzida no software GeoGebra. Um primeiro olhar sobre os relatórios produzidos permite afirmar que o uso do software foi profícuo, conforme destacado nas falas apresentadas ao longo dos relatórios. Percebe-se no decorrer dos textos produzidos que a complexidade da construção aumentava a cada etapa e a ação sobre o software conduziu os estudantes na criação de construções que envolviam mecanismos ou modelagens matemáticas através da geometria dinâmica.

A Figura 2 apresenta-se extratos dos relatos apresentados por três grupos de estudantes. Nota-se nos trechos destacados que o caráter interdisciplinar atribuído 
AÇÃO E MOVIMENTO: POSSIBILIDADES PARA A CONSTRUÇÃO DE CONCEITOS MATEMÁTICOS ATRAVÉS DOS PROJETOS DE GEOMETRIA DINÂMICA PELOS DISCENTES NA LICENCIATURA

pelos estudantes evidencia o processo da construção do conhecimento através de sucessivas assimilações e acomodações em busca de melhor compreender o objeto de estudo. Acredita-se que se o conhecimento matemático tivesse sido apenas transmitido aos estudantes na forma de aula expositiva, as relações estabelecidas por eles durante a elaboração e execução do projeto talvez não existissem da forma como foram produzidas. $\mathrm{Ou}$ seja, as relações matemáticas ou também as relações interdisciplinares destacadas pelos grupos de estudantes foram potencializadas pela ação sobre o objeto de estudo. Quando as relações aumentaram qualitativamente e quantitativamente, notou-se que a assimilação e acomodação também foram influenciadas, de modo que a alternância entre os equilíbrios e desequilíbrios fez com que a tomada de consciência fosse gradual e aumentasse a complexidade conforme a execução da proposta.

Justificativa: ao ver o uso do Excel no Geogebra, logo pensei em utilizá-lo. Dentre as ferramentas que uso no dia à dia, está é sem dúvida a que mais gosto, por ser dinâmica e por facilitar trabalhos com base de dados e cálculos de engenharia. No projeto, isso também foi relevante, uma vez que a partir de poucos pontos podemos obter uma figura complexa. Verifiquei o funcionamento da funçăo, a saber, Girar e usei no meu trabalho. A integração entre o Geogebra e outros software's o tornam mais dinâmico $e$ interessante na aprendizagem.

(a)

Sobre um primeiro olhar a construção parece simples, no entanto, ao analisar o passo a passo da construcão (disponível na janela "Protocolo de objeto), Figura 2, podemos observar que além de envolver conceitos matemáticos esta animação traz um manuseio desenvolvido desta ferramenta tecnológica fortemente envolvida no ensino de matemática.

(b)

IMPORTÂNCIA EDUCACIONAL E RELEVÂNCIA DO PROJETO PARA A GEOMETRIA

Nos primeiros anos do ensino fundamental é ensinado nas escolas como é formado e como funciona o sistema solar, mas devido à falta de recursos visuais para a observação e um aprofundamento do assunto, muitos estudantes acabam por desconhecer na prática e tendo dificuldades de aprender a forma como este processo ocorre. A fim de facilitar o entendimento dos alunos e auxiliar os professores na explicação da matéria, o grupo resolveu elaborar um Sistema Solar utilizando os recursos disponiveis no programa Geogebra. Para a realização deste trabalho foram necessários conhecimentos nas disciplinas de geografia, matemática, fisica e geometria, por isso, pode-se considerar como um projeto interdisciplinar. Em geografia devido à necessidade de se saber quais os corpos existentes no espaço, como estão localizados e o movimento que realizam em torno do sol. Em matemática e física, pois foi necessário o uso de fórmulas para o cálculo das velocidades e distâncias dos planetas. Já em geometria, para a construção do respectivo trabalho no programa Geogebra, foram utilizadas noç̃es de pontos, reta paralela, circunferência, intersecção entre objetos, elipses, entre outros conhecimentos em geometria adquiridos durante as aulas.

(c)

Figura 2: Amostra de relatos extraídas da produção dos estudantes Trechos do relatório do Grupo a) A, b) B e c) C. Fonte: Os autores.

Constata-se ao longo dos relatórios que as graduais e sucessivas tomadas de consciência ocorreram à medida que os obstáculos impostos pelo software ou pelo conteúdo de matemática necessário para a continuidade na execução da proposta foram superados. Os estudantes durante o processo cognitivo envolvido na elaboração da construção geométrica foram atores no processo

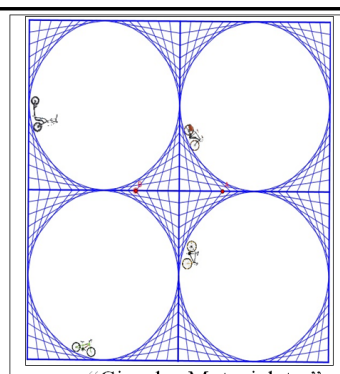

"Giro das Motocicletas"

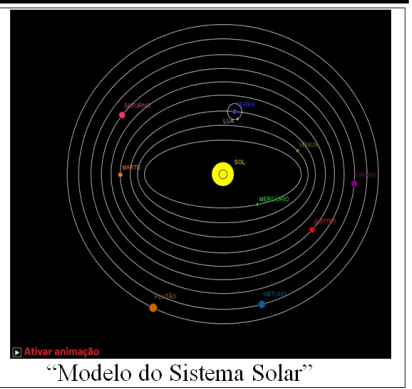

Figura 3: Exemplos de projetos produzidos pelos grupos de estudantes (2014/1). Fonte: Os autores.

de sua própria aprendizagem. Na construção do objeto dinâmico além de revisitar os conceitos matemáticos abordados na disciplina de Geometria Plana, houve a necessidade de conhecer outras ferramentas, conceitos ou ideias. Isso fez com que o sujeito tivesse que qualificar a sua ação e através do processo da regulação ativa fosse capaz de contornar a dificuldade.

As construções geométricas propostas pelos grupos de estudantes tinham movimento, ou seja, animações que relacionavam conceitos matemáticos da geometria. Ao propor que a construção no software tivesse movimento, estimulou-se que a ação praticada pelo estudante fosse gradualmente qualificada. Ou seja, tornase possível construir um mecanismo geométrico mais complexo quando as ações praticadas pelo sujeito são tais que permitem o avanço das construções mentais, através de sucessivas assimilações e acomodações, ou ainda de equilíbrios e desequilíbrios presentes durante todo o processo.

Na Figura 3 apresentam-se dois exemplos de objetos virtuais construídos pelos estudantes em 2014/1. Ambos têm caráter dinâmico e foram construídos utilizando relações matemáticas e também relações entre diferentes objetos matemáticos. O grupo que elaborou o objeto que simula o sistema solar investigou o comportamento das órbitas dos planetas, sendo que conseguiram através de relações matemáticas simular a velocidade de órbita de cada um dos elementos presentes na construção.

Portanto, constatou-se que o uso do software GeoGebra durante o primeiro semestre de 2014 contribuiu positivamente na elaboração do projeto. A geometria dinâmica nesse sentido surgiu como uma possibilidade para criar novas relações, através da ação do sujeito sobre o objeto de estudo. Ao motivar e estimular os estudantes, os processos de assimilações e acomodações permitiram que a tomada de consciência dos conceitos geométricos abordados na disciplina ocorresse de forma gradual e evolutiva. Finalmente, destaca-se que 
AÇÃO E MOVIMENTO: POSSIBILIDADES PARA A CONSTRUÇÃO DE CONCEITOS MATEMÁTICOS ATRAVÉS DOS PROJETOS DE GEOMETRIA DINÂMICA PELOS DISCENTES NA LICENCIATURA

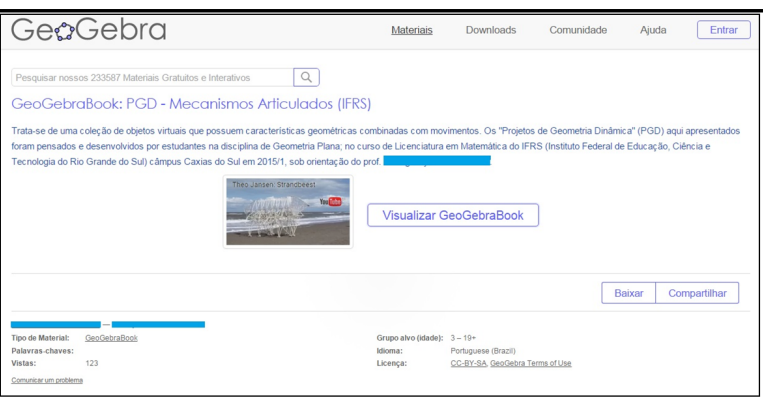

Figura 4: Página inicial do GeoGebraBook produzido a partir das construções dos estudantes. Fonte: <https://tube.geogebra.org/ material/show/id/1419157>

a tomada de consciência foi alcançada através do processo. Durante a execução da proposta verificou-se que a contribuição da informática foi essencial para que se chegasse ao final da pesquisa com os resultados apresentados e discutidos nessa seção.

\subsection{A turma de discentes 2015/1}

De maneira análoga que no primeiro semestre de 2014, ao final do primeiro semestre de 2015 os estudantes entregaram ao professor da disciplina os arquivos de construção do projeto e a produção textual. No segundo semestre de execução do projeto de geometria dinâmica, todos os arquivos produzidos pelos estudantes foram organizados e publicados na forma de um livro virtual, o "GeoGebraBook", tornando-se acessível através do repositório online de objetos virtuais produzidos no software GeoGebra. A Figura 4 ilustra a página de entrada do livro virtual.

Uma primeira análise sobre as produções textuais permite afirmar que o uso do software apesar das dificuldades apresentadas pelos estudantes na construção de determinados mecanismos, o mesmo foi bem aceito, conforme destacado nas falas apresentadas ao longo dos textos. De modo análogo a 2014/1 percebe-se no decorrer dos textos produzidos que a complexidade da construção aumentava gradualmente a cada nova etapa, e a ação sobre o software conduziu os estudantes na direção de elaborar métodos que visavam superar as dificuldades que se apresentavam durante a construção do projeto. Em 2015/1 foram produzidos ao todo oito projetos envolvendo construções geométricas que possuíam elementos de geometria dinâmica. Na Figura 5 ilustramos quais são os projetos apresentados pelos estudantes e que estão postados no livro virtual.

Nota-se em uma segunda análise sobre as produções textuais dos estudantes que o uso do software $\mathrm{Ge}$ oGebra tornou-se um desafio para os mesmos durante a elaboração do projeto. As falas dos grupos conver-

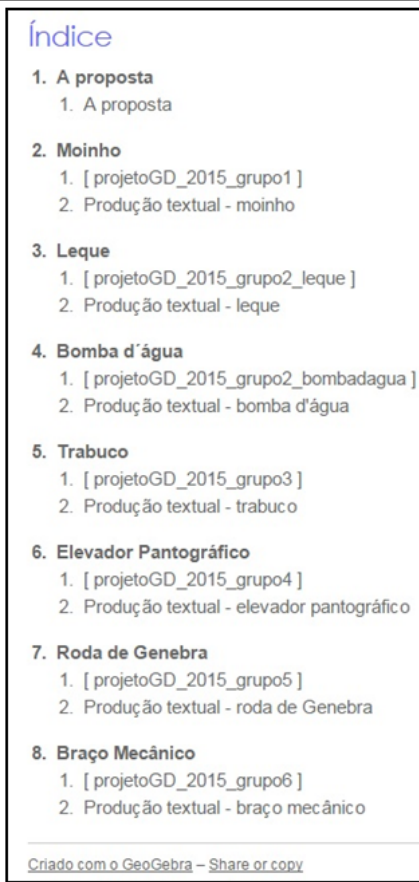

Figura 5: Lista de projetos no livro virtual. Fonte: $<$ https://tube. geogebra.org/b/1419157>

gem para a ideia de que o aprendizado durante o processo foi algo proveitoso e desafiante, onde para resolver determinada situação, imposta por uma necessidade do projeto, necessitou-se de pesquisas adicionais e considerável elaboração de novidades. Ao afirmar que a matemática faz parte do cotidiano (grupo 2) e sua compreensão é essencial para o entendimento da realidade que os cerca, nota-se que os estudantes assumiram o papel de sujeito que buscam a compreensão sobre os objetos em estudo, que procuram ultrapassar as barreiras impostas pelos objetos. Ao qualificar a ação sobre os objetos e sobre as formas de pensamento, os estudantes direcionaram sua própria aprendizagem com o intuito de conhecer mais o objeto em estudo, tornando assim as direções do binômio assimilação/acomodação mais próximas dos centros do objeto e sujeito.

Ainda vale ressaltar que o uso do software na realização do projeto estimulou nos estudantes a possibilidade de propor esse tipo de atividade em sala de aula, conforme destaca o grupo 3. Percebeu-se que a maioria dos estudantes envolvidos com a proposta de projeto em 2015/1 desconhecia o software, e que anterior à disciplina os assuntos de Geometria Plana (quanto tratados) tinha sido predominantemente expostos da forma tradicional. Portanto, considera-se profícuo que o uso do software tenha contribuído além da formação acadêmica desses discentes no que se refere aos conceitos 
AÇÃO E MOVIMENTO: POSSIBILIDADES PARA A CONSTRUÇÃO DE CONCEITOS MATEMÁTICOS ATRAVÉS DOS PROJETOS DE GEOMETRIA DINÂMICA PELOS DISCENTES NA LICENCIATURA

$\begin{gathered}\text { Em suma, pode-se dizer que o projeto de mecanismo articulado foi muito proveitoso, pois } \\ \text { possibilitou um aprofundamento dos conteúdos da disciplina de geometria plana, bem como o }\end{gathered}$
$\begin{gathered}\text { conhecimento de um novo software, muito interessante para o estudo, não só de geometria, } \\ \text { mas também de outros conteúdos matemáticos: o geogebra. } \\ \text { Trecho do relatório do Grupo } 4\end{gathered}$
Em nossa sociedade podemos identificar diversos movimentos com padrões
geométricos. Com isso podemos ver que a matemática e seus ramos estão muito presentes em
nosso cotidiano e não apenas em números e suas operações. Com isso, tendo auxilio do software
Geogebra, escolhemos um objeto e uma máquina que possuem movimentos geométricos planos
para analisarmos. Foram escolhidos: o leque e um sistema de bombeamento de água criado no
Oriente Médio durante o periodo da Idade Média.
Trecho do relatório do Grupo 2
Muito foi aprendido neste trabalho, além de retomarmos todos os
conceitos matemáticos aprendidos em aula durante o primeiro semestre,
conseguimos ter algumas noções do software, cujo manuseio é bem divertido.
Consequentemente se pode criar nele inúmeros projetos exóticos e assim
despertar o interesse dos alunos.
Trecho do relatório do Grupo $\underline{3}$

Figura 6: Amostra de relatos extraídas da produção dos estudantes. Fonte: Os autores.

de Geometria Plana, uma vez que se espera no futuro a condução por parte destes, no papel de professores atuantes, a elaboração de futuros projetos envolvendo geometria dinâmica com seus alunos. Na Figura 6 ilustrase através de trechos extraídos das produções textuais o que se dissertou nos últimos parágrafos.

Quanto aos aspectos da tomada de consciência notou-se uma evolução qualitativa dos estudantes enquanto envolvidos com a proposta do projeto. Constatou-se que a combinação dos fatores: o melhoramento de sua ação sobre os objetos em estudo e a tentativa de elaboração de novidades foi essencial para que os estudantes alcançassem sucesso na elaboração dos projetos pensados inicialmente. O constante esforço intelectual dispensado na construção do projeto fez com que o aperfeiçoamento da ação e melhor conhecimento sobre o software desafiassem os sujeitos na direção do conhecimento ao longo do semestre.

Percebeu-se que os graduais e sucessivos avanços ao longo do semestre na elaboração da proposta fizeram com que progressivamente as ações assimiladoras e acomodadoras fossem sendo aperfeiçoadas. Tal aperfeiçoamento possibilitou aos sujeitos melhorar sua capacidade de elaboração e melhoramentos de ideias, portanto a regulação ativa tornou-se então o motor dos diferentes níveis da tomadas de consciência observados no decorrer do processo. Logo, devido aos diferentes níveis da tomada de consciência foi possível perceber o quanto cada grupo de estudantes avançou em termos de complexidade na elaboração do projeto.

Alguns projetos apresentaram uma construção de mecanismo complexa e que exigiu pesquisas além da sala de aula. Este tipo de momento onde o sujeito busca por si próprio determinado conhecimento deu-se pelo fato do objeto se apresentar de compreensão não ime-

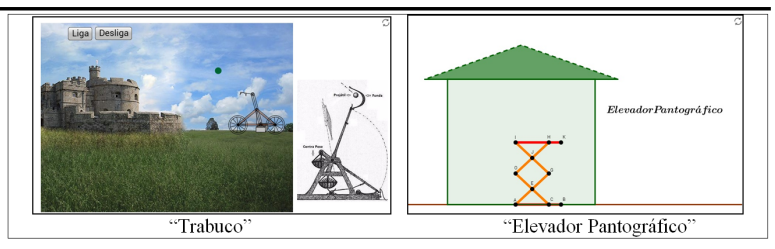

Figura 7: Exemplos de projetos produzidos pelos grupos de estudantes $(2015 / 1)$. Fonte: Os autores.

diata, impondo ao sujeito que tenta compreendê-lo os mais diversos desafios e impasses que não o permitiam avançar e alcançar seus objetivos. Esse fato também pode ser considerado como relevante na elaboração do projeto, uma vez que estimulou os envolvidos pela busca por conhecimentos além dos discutidos na disciplina de Geometria Plana. A Figura 7 ilustra dois projetos elaborados pelos grupos.

\section{CONCLUSÕES E CONTRIBUIÇÕES COM A PESQUISA}

Ao final da presente pesquisa, constatou-se que a execução de um projeto envolvendo geometria dinâmica tornou as aulas da disciplina Geometria Plana significativa para os estudantes. Sobre o uso da geometria dinâmica para a construção de conceitos matemáticos e os possíveis ganhos na aprendizagem, Gravina e Santarosa (1999) contribuem:

\footnotetext{
O aluno cria seus próprios modelos (tomado aqui em sentido amplo) para expressar ideias e pensamentos. Suas concretizações mentais são exteriorizadas. Uma vez construído o modelo, através dos recursos do ambiente, o aluno pode refletir e experimentar, ajustando e/ou modificando suas concepções. Nesse sentido, os ambientes são veículos de materialização das ideias, pensamentos e mais geralmente de ações do sujeito. (GRAVINA; SANTAROSA 1999 p. 81)
}

Verificou-se com a experimentação durante os dois semestres da pesquisa que houve contribuições no processo de aprendizagem da geometria. Ou seja, oportunizar ao estudante a vivência de situações favoráveis ao desequilíbrio desafia a atividade mental, a qual conduz o sujeito à regulação ativa, ou criação de novidades. Destaca-se que o processo de elaboração da novidade e criatividade é essencial em matemática, pois possibilita segundo Piaget, um avanço qualitativo na forma e estruturação do pensamento.

É notável que o uso tecnologia digital de acordo com o referencial teórico consultado (GIRALDO, 2012, PAPERT, 2008; BONA, 2012, GOMES; SOUZA; SIQUEIRA, 2012, VEEN; VRAKKING. 2009, MILANI, 2001) possibilitou uma reflexão sobre 
AÇÃO E MOVIMENTO: POSSIBILIDADES PARA A CONSTRUÇÃO DE CONCEITOS MATEMÁTICOS ATRAVÉS DOS PROJETOS DE GEOMETRIA DINÂMICA PELOS DISCENTES NA LICENCIATURA

o desenvolvimento de novas competências e habilidades nos estudantes envolvidos nessa pesquisa realizada durante dois semestres. Espera-se que os níveis de tomada de consciência alcançada pelos estudantes (futuros professores de matemática) no decorrer da proposta influencie positivamente a sua prática enquanto docente, pois acredita-se que propor a investigação de conteúdos da Geometria Plana através da construção de modelos dinâmicos, a matemática estudada enriquece e qualifica a qualidade do pensamento de todos os sujeitos envolvidos.

\section{REFERÊNCIAS}

BARBOSA, R. M. Ambientes Virtuais de Aprendizagem. Porto Alegre: Artmed, 2005.

BONA, A. S. D. Espaço de Aprendizagem Digital da Matemática: o Aprender a Aprender por Cooperação. Tese (Doutorado em Informática na Educação) Programa de Pós-Graduação Interdisciplinar de Novas tecnologias, UFRGS, Porto Alegre, 2012.

GIRALDO, V. Integrando geometria e funções: Gráficos dinâmicos. Revista do Professor de Matemática (RPM), São Paulo, v. 30, n. 79, p. 39 - 46, 2012. $3^{\circ}$ quadrimestre.

GOMES, A. S.; SOUZA, R. J.; SIQUEIRA, R. Resistência ao uso de TIC no ensino. Educar com o Redu. Recife: Redu, Educational Technology, 2012. P.100-102.

GRAVINA, M. A.; SANTAROSA, L. M. C. A aprendizagem da matemática em ambientes informatizados. Informática na Educação: teoria \& prática. PGIE-UFRGS, v. 2, n. 1, 1999.

MILANI, E. A informática e a comunicação matemática. In: SMOLE, K. S.; DINIZ, M. I. (Ed.). Ler, escrever e resolver problemas: Habilidades básicas para aprender matemática. Porto Alegre: Artmed, 2001. p. 176-200.

PAPERT, S. Logo: computadores e educação. São Paulo: Brasiliense, 1988.

A máquina das crianças: repensando a escola na era da informática. Porto Alegre: Artmed, 2008.

PIAGET, J. A Tomada de Consciência. São Paulo: EDUSP/Melhoramentos, 1977.

Fazer e Compreender. São Paulo:

EDUSP/Melhoramentos, 1978.

Conex. Ci. e Tecnol. Fortaleza/CE, v. 9, n. 4, p. 48 - 56, dez. 2015 